\title{
Analysis on the Talent Training Strategy of International Baijiu Sommelier
}

\author{
ZHU Wenjun \\ Administrative Office of Foreign Languages School, \\ Sichuan University of Science and Engineering \\ No. 188, University Town, Lingang Economic and Technological Development Zone, \\ Yibin City, Sichuan Province, China
}

Tel: 86-137-9556-6181_E-mail: 47032998@qq.com

Received: March 10, 2020 Accepted: June 10, 2020 Published: June 28, 2020

doi: 10.5296/jsss.v7i2.17290 URL: https://doi.org/10.5296/jsss.v7i2.17290

\begin{abstract}
Chinese spirits (Baijiu) is one of the eight major spirits in the world, with annual output accounting for one third of the world's distilled liquor, but Baijiu sales in the international market account for only $0.76 \%$. Baijiu, with its long history, is well known in China, but its international recognition is very limited. To share Baijiu with Chinese characteristics with the world's friends, we need a group of people who not only are familiar with the history, culture and drinking style of Chinese Baijiu, but also have the fluent language ability and certain international cross-cultural communication ability. Talent is the hard core of development; to achieve the internationalization of Chinese Baijiu depends on the training of professionals. The "International Baijiu Sommelier" program co-sponsored by Sichuan University of Science and Engineering (SUSE) and Wuliangye Group is to fill this talent vacancy. This paper focuses on the cultivation strategy of "international Baijiu sommelier".
\end{abstract}

Keywords: Baijiu, Sommelier, Training, Strategy

\section{Preface}

Baijiu, with its long history, is well known in China, but its international recognition is very limited. The most difficult point to promote Baijiu internationalization lies in the lack of professional talents in fact. To share Baijiu with Chinese characteristics with the world's friends, we need a group of people who not only are familiar with the history, culture and drinking style of Chinese Baijiu, but also have the communicative language ability and 
certain international cross-cultural communication ability.

In cooperation with China's leading Baijiu producer-Wuliangye Co., Ltd., the opening ceremony of the international Baijiu sommelier class was held at Sichuan University of Science and Engineering on the afternoon of June 22, 2018, marking the official opening of the first Chinese Baijiu sommelier training program. As a member of the Sichuan Baijiu International Communication Research Center, I have the honour to serve as the Class Adviser of the student class. Many liquor industry leaders and media friends attended the ceremony, including Mr. Song Yushu, Secretary-General of China Liquor Industry Association, Mr. Liu Zhenguo, Deputy Secretary-General of Marketing Professional Committee of China Liquor Industry Association, Mr. Zhao Dong, Deputy Chief Engineer of Wuliangye Co., Ltd., Ms. Yang Yunxia, Minister of the Party and Mass Work of Wuliangye Co., Ltd., Mr. Qiao Zongwei, Director of Technical Research Centre of Wuliangye Co., Ltd., Mr. Tuo Xianguo, President, Ms. Gong Min, Deputy Party Secretary, Mr. Yan Jie, Vice President, and Mr. Gao Xiaolin, Vice President of Sichuan University of Science and Engineering, and leaders from Yibin Qinglang Ecological Baijiu Co., Ltd., Yibin Zijun Denggong Baijiu Co., Ltd., Yibin Xufu Baijiu Co., Ltd., Yibin Jinliangzao Baijiu Co., Ltd., Yibin Jinxilai Baijiu Co., Ltd. as well as media representatives from Huaxia Liquor News, Sichuan Economic Daily, Yibin Municipal TV Station, Yibin Daily, Yibin Evening News, Yibin News Network etc..

The launch of the first "International Baijiu Sommelier" class aims to train outstanding international sommeliers with passion and dedication, unity and cooperation, and broad knowledge of humanities and social sciences and strong cross-cultural communication skills for famous liquor companies such as Wuliangye, which is both the first domestic and international initiative. The successful opening ceremony attracted the attention of a group of industry and media people at home and abroad, who showed great interests and supports to the program.

\section{The Definition of International Baijiu Sommelier}

International Baijiu Sommelier, a loanword of "wine sommelier", is distinguished from the wine sommelier in the general sense. In general, sommelier comes from French and refers exclusively to the waiter in charge of drinks in hotels and restaurants, who has professional wine knowledge and skills to provide wine service and consultation to guests and is in charge of the menu design, wine identification, evaluation, procurement, sales and wine cellar management. A good sommelier should not only have the basic knowledge and professional skills of wine, but also know how to design side dishes, have the ability to appreciate wine, have a deep evaluation foundation for wine, and be familiar with the requirements of wine procurement, and be good at managing wine cellar.

For the Chinese Baijiu drinking group, Baijiu is a hobby drink; however, with the improvement of people's living standards, drinkers' requirements for Baijiu are also changing. Nowadays, people drink not only simply for the need of addiction, stimulation or relaxation, but also for the appreciation of its color, fragrance and taste, and style of liquor. Drink is regarded as a kind of beautiful enjoyment, making the content of life more colorful. Such a 
change makes Baijiu become a drink that drinkers need to have a certain professional knowledge about it, then they can only experience the charm of it. Therefore, a Baijiu sommelier is required to have the similar expertise of a wine sommelier for wine. In addition, the international Baijiu sommeliers have the responsibility of sharing the Baijiu culture with global partners. This requires them to have broad international vision, innovative spirit and practical ability, solid bilingual foundation, broad knowledge of humanities and social sciences and strong cross-cultural communication skills.

In recent years, with the Chinese Baijiu market booming, sommelier, the heavyweight figure of high-end restaurants and hotels, has also begun to become the market's hottest professional, said Mr. Song Yushu, Secretary-General of China Liquor Industry Association. Therefore, the market demand for liquor sommeliers is huge.

\section{Training Strategy}

One who has talents feels easy and one who has no talents feels anxious. General Secretary Xi Jinping stressed at the opening ceremony of the CPC's 19th National Congress that talent is a strategic resource to achieve national rejuvenation and win international competition initiative. It is necessary for us to adhere to the principle of Party management of talents, gather the world's outstanding talents who are to be fully given role to play and speed up the construction of talents empowering the country. We need to implement an active, open and effective talent policy to bring the outstanding talents outside the Party and both home and abroad into the great struggle of the Party and the people based on our wisdom of finding talents, sincerity of love to talents, courage to use talent, inclusive magnanimity to talents, and good practice to attract talents. To build an open view of talent in the great era of talent, we need to use an open, a tolerant and respectful attitude to promote the work of talent. In the cultivation of talents in liquor industry, it is necessary to mobilize the industry, enterprises and scientific research institutions to work together to cultivate the international talents in the industry.

To cultivate international Baijiu sommelier requires meticulous and conscientious work in every link of training. From the selection of students, to the training program, the arrangement of teachers, and the practice of students, we need to fully consider the professional skills and qualities required by international Baijiu sommelier, and realize the ultimate goal of training international Baijiu sommelier.

\subsection{The Selection of Students}

Ram Charan, in his book The High Essential Leader- How to Grow Fast, Take on New Responsibilities, and Make an Impact, argues that high-potential people should have the characteristics of "daring to conceive a big picture, daring to break through the impossible, and being good at building an ecosphere". [3] The characteristics of these three aspects have great relevance to personal characters and thinking style. Therefore, in the talent selection stage, if we can find students with the above three characteristics, we can make the later training twice the result with half the effort.

There are nearly 40,000 students in SUSE and the selection work is carried out among all 
students including junior college students, undergraduates and postgraduates. Through the primary and secondary selections and interview, according to their career pursuit, bilingual skills, communication skills, adaptability, cooperation spirit, service awareness and other dimensions, we can finally sort out the first batch of Baijiu sommelier candidate students.

The order of interview and speech are determined by drawing lots. The full mark is 100 including the language expression ability, contingency ability, comprehensive accomplishment, overall image etc. of candidates; the average from the judges is the interview score of each candidate. Candidates in the final top 30 according to the score of the contestants can be admitted to the international Baijiu sommelier class.

\subsection{The Training Curriculum}

Closely adhering to the goal of cultivating the talents of the international Baijiu sommelier, the core members of the program have spent three months on the design and investigation and finally established the final form of the curriculum system based on the full contact with the excellent experts or teachers of various subjects. The training curriculum cover three sections: cultural theory curriculum, social practice curriculum and quality development curriculum. The teachers are Wuliangye senior experts, Baijiu industry experts, translation experts, etiquette experts and foreign language backbone teachers. As for the form of teaching organization, the organizational principles of combining theory with practice, combining classroom teaching with special lectures, and combining school teaching with enterprise experience are established.

The curriculum include: overview of Chinese Baijiu, Chinese Baijiu products and services, Chinese Baijiu distilling (focusing on the technology of Wuliangye), the unique advantages of Wuliangye, Chinese Baijiu customs (focusing on Yibin's local style), liquor lexicography, translation practice (focusing on liquor translation), interpretation practice (focusing on liquor translation), cross-cultural communication, international trade (focusing on liquor trade), international liquor market, business English writing, international business negotiation skills, etc.

The intensity of the curriculum is equivalent to that of a dual degree. All the curriculum are offered over the weekend, which does not affect students' main course but allows students to make full use of their spare time to learn new skills.

\subsection{The Extracurricular Practice}

Apart from the classroom knowledge, students can participate in various social or school practice activities, such as liquor doctrine show, professional lectures on alcohol offered by industry leaders, liquor tasting contest and liquor blending competition of national universities, Luzhou liquor fair and Chengdu sugar and liquor fair, internship in five-star hotels, or direct practice at the sub-companies of Wuliangye, etc. For instance, Li Hang, the royal sommelier, offered a lecture on the origin, concept, work function, professionalism and career planning of a sommelier, and showcased the manners of a sommelier: opening, waking, pouring and drinking of wine. This kind of activity broadens the horizon of the international Baijiu sommeliers and let them grasp the practice skill, fully manifesting the important 


\section{Al Macrothink}

function which the theory unifies the practice played in talents training.

\section{Conclusion}

The launch of the first international Baijiu sommelier class is a major measure taken by SUSE to carry out the combination of government, industry, university, research institutions and applications, provide the service to the local and promote the development of local economy. Through the training of the above three aspects via three approaches, we can train a group of excellent international Baijiu sommelier talents, in other words, we can export a group of excellent international talents for famous liquor enterprises, and make an international marketing talents reserve for the Chinese liquor industry. The sommeliers can get the professional knowledge and tell the Chinese liquor story well with sommeliers' etiquette and services as well as in Baijiu international promotion, share the Chinese Baijiu culture with foreign friend, who can share the Chinese Baijiu as well.

\section{Acknowledgement}

The research is financed by Research Center for International Transmission of Sichuan Liquor Culture. Thanks for Prof. Yun Hong, Liao Guoqiang, Wang Hongyuan, Huang Qiang, Huang Yan, Sichuan University of Science and Engineering.

\section{References}

Charan, R. (2018). The High Potential Leader-How to Grow Fast, Take on New Responsibilities, and Make an Impact. Trans. Yang Yimei. Beijing: China Machine Press.

Wang, Y. H, \& Miao, Lv. (2018). The Roadmap of Talent Development. Beijing: China Social Sciences Press.

Wu, G. Q. (2008). Baijiu Tasting and Evaluation. Beijing: China Light Industry Press.

\section{Copyright Disclaimer}

Copyright for this article is retained by the author(s), with first publication rights granted to the journal.

This is an open-access article distributed under the terms and conditions of the Creative Commons Attribution license (http://creativecommons.org/licenses/by/4.0/). 